Case Report

DOI: http://dx.doi.org/10.18203/issn.2454-5929.ijohns20201298

\title{
Unusual presentation of a unilateral choanal atresia in an adult: a case report
}

\author{
Sunil K. C.*, B. Y. Praveen Kumar, Kiran Mali, Varna Ravindran M. K.
}

Department of Otorhinolaryngology, Mysore Medical College and Research Institute, Mysore, Karnataka, India

Received: 24 January 2020

Accepted: 06 March 2020

*Correspondence:

Dr. Sunil K. C.,

E-mail: drsuniliyengar@gmail.com

Copyright: ( ) the author(s), publisher and licensee Medip Academy. This is an open-access article distributed under the terms of the Creative Commons Attribution Non-Commercial License, which permits unrestricted non-commercial use, distribution, and reproduction in any medium, provided the original work is properly cited.

\begin{abstract}
Choanal atresia is an uncommon congenital abnormality of nasal airway characterised by the complete obliteration of choana. Unilateral choanal atresia is more common as compared to bilateral choanal atresia. A case of unilateral nasal obstruction in an adult which was initially diagnosed as chronic rhinosinusitis and was posted for endoscopic sinus surgery at a secondary referral hospital. Increased nasal bleeding during the surgery led to the surgeon abandoning the procedure and was referred to Mysore Medical College and Research Institute. On detailed evaluation, unilateral choanal atresia of right sided was noted. It was subsequently managed by endoscopic recanalization of the posterior choana. This case of unilateral choanal atresia in an adult is being reported here for the rarity of its presentation. A high level of clinical suspicion is necessary to diagnose such cases and to prevent avoidable complications during routine endoscopic surgeries. Resection of posterior part of nasal septum to create uni-choana negates the need for stenting post-operatively.
\end{abstract}

Keywords: Unilateral choanal atresia, Adult, Recurrent sinusitis

\section{INTRODUCTION}

The choanal atresia was first described by Roederer in 1755. ${ }^{1}$ Choanal atresia is an uncommon congenital abnormality of nasal airway characterised by the complete obliteration of choana. Unilateral choanal atresia is more common as compared to bilateral choanal atresia. It is due to persistence of the naso-buccal membrane. The occurrence of choanal atresia is 1 out of 5000-8000 births. $^{2}$ Bilateral choanal atresia presents in early life with acute respiratory distress as neonates are obligate nasal breathers in contrast with unilateral nasal atresia who presents later with unilateral obstruction, chronic sinusitis and may not become apparent until their early adulthood. ${ }^{3}$ Choanal atresia is bony type in $90 \%$ cases $(30 \%$ pure bony and $70 \%$ mixed bony and membranous) and $10 \%$ cases are membranous. ${ }^{4}$ Choanal atresia can be associated with other syndrome like CHARGE (coloboma, heart defect, atresia choana, retardation of growth, genital anomalies and ear abnormalities), Treacher-Collins, Pfeiffer, DiGeorge syndrome. ${ }^{5}$ We present a rare case of unusual presentation of unilateral choanal atresia in a 23 year old young adult male and describe the clinical features, evaluation, diagnosis and surgical procedure.

\section{CASE REPORT}

A 23 years old man was referred to our department from a secondary referral hospital, Mysore, Karnataka, India. He was diagnosed as a patient of chronic rhinosinusitis and was taken up for endoscopic sinus surgery. During surgery, there was frank pus and bleeding which could not be controlled. Hence the procedure was aborted, nasal packing was done and referred to our institute.

Patient gives the history of right nasal mucoid discharge since 1 year with episodes of right sided headache. 
Patient gave history of right nasal obstruction only when specifically asked for and said he had never noticed it.

No history of bluish discolouration of skin at birth, trauma to nose, bleeding from nose, anosmia or hyposmia.

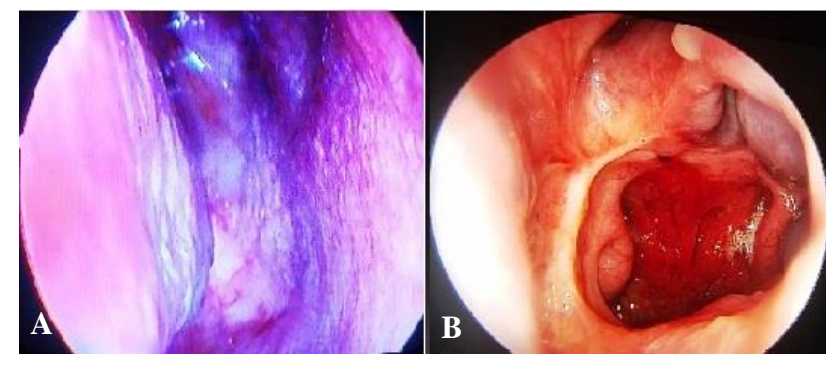

Figure 1 (A and B): Pre-op (right choanal atresia) and postoperative endoscopic (uni-choana).

Patient underwent diagnostic nasal endoscopy using $0^{0}$ endoscope in right nasal cavity frank pus and blood was noted, suctioning was done, right posterior choana was completely obliterated without visualization of nasopharynx (Figure 1).

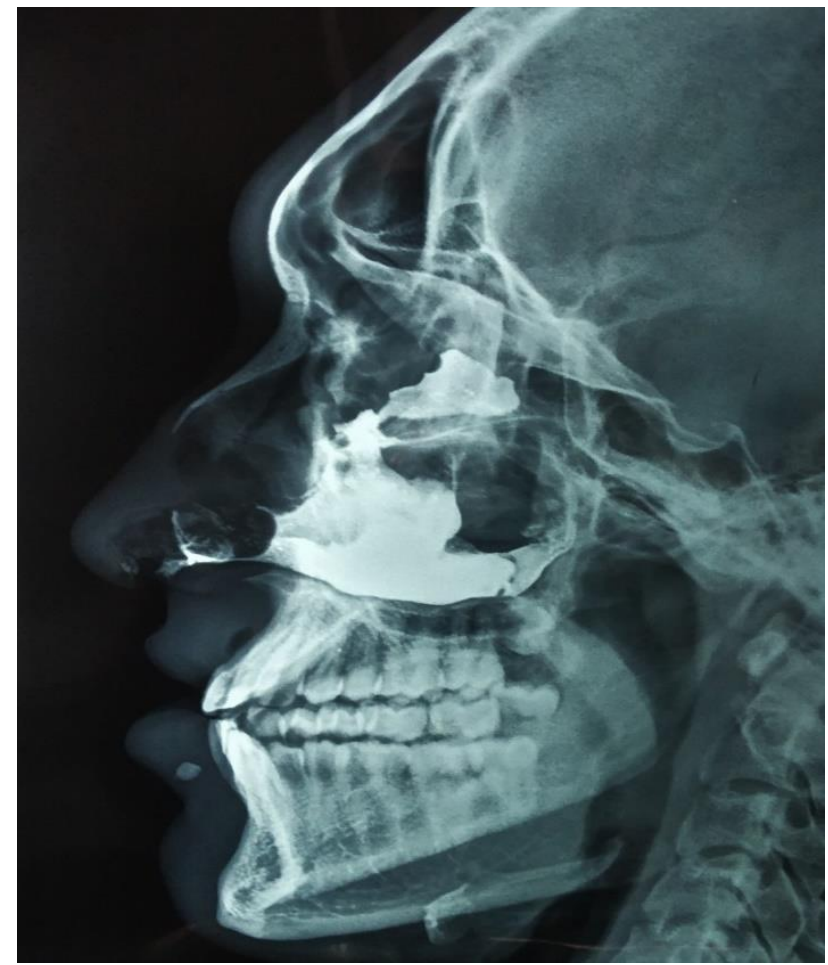

Figure 2: Contrast radiograph of nasopharynx showing inability of communication of nasal cavity with nasopharynx.

X-ray nasopharynx lateral view was taken after instillation of barium drops in right nasal cavity showing pooling of contrast in right nasal cavity with no obvious communication between right nasal cavity and nasopharynx (Figure 2).

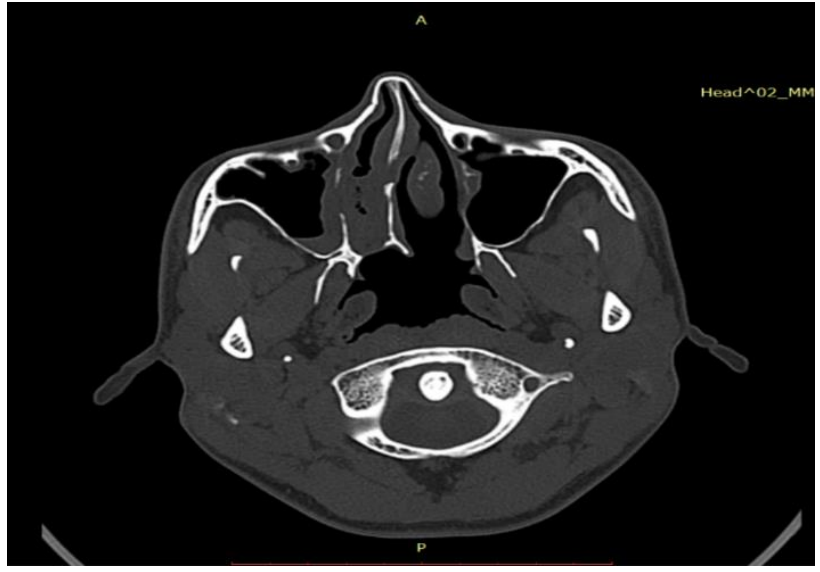

Figure 3: Computed tomography of paranasal sinus axial view.

Computed tomography paranasal sinus $1 \mathrm{~mm}$ cuts showing mixed fibrous or bony membrane at right choana, collection in right nasal cavity, right maxillary sinusitis, S shaped deviated nasal septum (Figure 3).

Patient was subsequently treated with parenteral antibiotics to control the infection and was prepared for surgery. Endoscopic visualization on operative table confirmed the diagnostic endoscopic finding. Transnasal endoscopic recanalization of the right posterior choana was done under general anaesthesia. The persistent nasobuccal membrane was found to be mixed (bony and membranous). The posterior aspect of nasal septum was resected for upto $1 \mathrm{~cm}$ from its posterior edge to create a uni-choana. The idea was to visualize openings of both the pharyngo-tympanic tube through a single nasal cavity. No intra-operative stent or mitomycin $\mathrm{C}$ application was used. Patient was advised nasal douching in the postoperative period as any endoscopic sinus surgery.

\section{DISCUSSION}

Choanal atresia is an uncommon congenital abnormality of nasal airway characterised by the complete obliteration of choana. It is due to persistence of the naso-buccal membrane. It was first described by Roederer in $1755 .^{1}$ Unilateral choanal atresia is more common as compared to bilateral choanal atresia. It usually presents later in life with unilateral nasal obstruction, recurrent rhinorrhoea and foul-smelling nasal discharge. Choanal atresia is bony type in $90 \%$ cases (30\% pure bony and $70 \%$ mixed bony and membranous) and $10 \%$ cases are membranous. ${ }^{4}$

Diagnostic endoscopy reveals absence of posterior choana with a smooth mucosal cover overlying it. Computerized tomography reveals a thickening of the vomer, bowing of the lateral wall of the nasal cavity and fusion of bony elements in choanal region. ${ }^{6}$

Many different techniques are described for the management of the same with each having its own 
advantages over visualization, ease of access, need for stenting and post-operative cicatrisation.

Hengerer reported $18 \%$ of patients who underwent transnasal resection developed restenosis requiring revision surgery. ${ }^{7}$ Transpalatal resection offers good exposure to the choanal abnormality, posterior vomer and lateral nasal wall. A U-shaped flap is raised on the palate, conserving the greater palatine arteries. The choanal abnormality can be removed under direct visualization. Ferguson reported $90 \%$ of patients treated with transpalatal resection did not require any further surgery. ${ }^{8}$ However, it is associated with a high rate of crossbite abnormalities. ${ }^{9}$ Other possible complications are palate flap necrosis or fistula.

Controversy exists over the use of stenting as well as use of fibroblast inhibitors (mitomycin-c). Postoperative cicatization and stenosis is the commonest indication for the use of these. Various methods of stenting have been described by multiple authors. Materials used as stents are modified endotracheal tube, silastic stents and Teflon stents. Silastic and Teflon stents are softer. Stents are regularly instilled with saline and suctioned to prevent crusting and blockage. Traditionally stents are left in-situ for 6-8 weeks for re-epithelization of the neochoana. ${ }^{10}$

However, stents are not without its risk, such as patient discomfort, septal or columellar necrosis, nasal and paranasal infection and intranasal synechiae. In view of the morbidities associated with stenting, several studies argued that postoperative stenting is not a must. ${ }^{11,12}$

Endoscopic resection was first reported by Stankiewicz. ${ }^{13}$ Availability of high resolution cameras with endoscopes has revolutionized the scope and extent of nasal surgeries. The management of choanal atresia too have benefitted from the same. Endoscopic surgeries have a very good visualization and with precise instrumentation with microdebrider and drill, removal of atretic segment can be done with more precision, hence, reducing the need to protect the denuded tissue from exuberant granulation tissue and synechiae formation.

Our case is being reported not only as a case of unilateral choanal atresia in an adult; but also for its unusual manner of its presentation in a teritiary care hospital. The patient was diagnosed as chronic rhinosinusitis and was taken up for Endoscopic sinus surgery. During the surgery, due to drainage of pus and uncontrolled bleeding, the nasal cavity was packed and referred to our institute.

Thorough history taking, proper clinical examination and a high degree of clinical suspicion is necessary in diagnosing such cases. On endoscopic recanalization of the posterior choana, the posterior aspect of the septum upto $1 \mathrm{~cm}$ was resected to prevent post-operative stenosis or cicatrisation; thus, in turn avoiding the need for stenting or use of fibroblast inhibitors (mitomycin-c) and hence negating the complications associated with it.

\section{CONCLUSION}

Unilateral choanal atresia usually presents in younger age groups but can present very late in adults with symptoms like rhinorrhoea and nasal obstruction. Thorough history taking, proper clinical examination and a high degree of clinical suspicion is necessary in diagnosing such cases. Transnasal endoscopic resection is the technique of choice owing to its favourable outcome and lower morbid as compared to transpalatal approach. Resection of posterior end of septum avoids the need for stenting or application of fibroblast inhibitors.

Funding: No funding sources

Conflict of interest: None declared

Ethical approval: Not required

\section{REFERENCES}

1. Kelvin M. Kwong. Current updates in choanal atresia. Frontiers Paediatrics. 2015;3:52.

2. Anajar S, Hassnaoui J, Rouadi S, Abada R, Roubal M, Mahtar M. A rare case report of bilateralchoanal atresiain anadult. Int J Surg Case Rep. 2017;37:1279

3. Duggal P, Kajol R, Duggal KK. Unilateral choanal atresia presentation in adults. Indian $\mathrm{J}$ Otolaryngol Head Neck Surg. 2005;57(4):345-7.

4. Tan HY, Noor AM, Anuar, Sawali H. Bilateral choanal stenosis in a craniosynostosis child: a case report. Int J Otorhinolaryngol Head Neck Surg. 20195(1):184-6.

5. Nanda MK, Assa'ad AH. Unilateral choanal atresia in child with recurrent infections. J Allergy Clin Immunol Pract. 2014;2(6):820-1.

6. Wetmore RF, Mahboubi S. Computed tomography in the evaluation of choanal atresia. Int $\mathbf{J}$ Pediatr Otorhinolaryngol. 1986;11:265-7.

7. Hengerer AS, Brickman TM, Jeyakumar A. Choanal atresia: embryologic analysis and evolution of treatment, a 30-year experience. Laryngoscope. 2008;118(5):862-6.

8. Ferguson JL, Neel HB 3rd. Choanal atresia: treatment trends in 47 patients over 33 years. Ann Otol Rhinol Laryngol. 1989;98(2):110-2.

9. Freng A. Growth in width of the dental arches after partial extirpation of the mid-palatal suture in man. Scand J Plast Reconstr Surg. 1978;12(3):267-72.

10. Brown OE, Pownell P, Manning SC. Choanal atresia: A new anatomic classification and clinical management applications. Laryngoscope. 1996;106:97-101.

11. Saafan ME. Endoscopic management of congenital bilateral posterior choanal atresia: value of using stents. Eur Arch Otorhinolaryngol. 2013;270:12934. 
12. Schoem SR. Transnasal endoscopic repair of choanal atresia: Why stent? Otolaryngol Head Neck Surg. 2004;131:362-6.

13. Ramsden JD, Campisi P, Forte V. Choanal atresia and choanal stenosis. Otolaryngol Clin N Am. 2009;42:339-52.
Cite this article as: Sunil KC, Kumar BYP, Mali K, Varna RMK. Unusual presentation of a unilateral choanal atresia in an adult: a case report. Int $\mathbf{J}$

Otorhinolaryngol Head Neck Surg 2020;6:780-3. 